Ethiopian Journal of Environmental Studies \& Management 9(Suppl. 1): 829 - 840, 2016.

ISSN:1998-0507

doi: http://dx.doi.org/10.4314/ejesm.v9i1.3S

Submitted: May 11, 2016

Accepted: November 18, 2016

\title{
A SPATIAL DECISION SUPPORT SYSTEM FOR SPECIAL HEALTH FACILITY LOCATION PLANNING IN DEVELOPING REGIONS
}

\author{
OLAYINKA, W. OTUN
}

Department of Geography, Olabisi Onabanjo University, Ago-Iwoye, Nigeria

Email: otunwo@yahoo.com

\begin{abstract}
Access to healthcare is a determinant of the wellbeing of the people. Planning the location and distribution of health facilities to ensure efficiency and equity in the face of limited resources can be challenging, especially where the type of care requires expensive equipments and specialists. This study attempts to provide a spatial decision support system (SDSS) to select specific locations for provision of mental health care out of existing health centres. The SDSS in this study uses a geographic information system (GIS) and location-allocation models. The data used in the SDSS include the coordinates of the location of the mental health facilities, the coordinates and population of the settlements and data on the roads and footpaths in the study area. The empirical results from the application of the SDSS framework shows that the average distance travelled in the existing configuration of mental health care centres (MHC) could be reduced from $15.3 \mathrm{~km}$ to $14 \mathrm{~km}$ by adopting a model plan. It is also shown that $74.85 \%$ of the settlements are more than ten kilometers from the nearest MHC. In order to minimize travel distance and maximize coverage of the population the minimize facilities, model option of the SDSS shows that 21 facilities are required to ensure that the average travel distance is $9.4 \mathrm{~km}$ and that $98.6 \%$ of the settlements are not more than $20 \mathrm{~km}$ from the nearest MHC. Decision makers can use the SDSS discussed in this study to achieve efficiency or equity in the provision of health services. Thus it is hoped that health planners would adopt these techniques and tools to make their location decisions more efficient, reduce inequities and be rational in the use of resources.
\end{abstract}

Key Words: Mental Health Facilities, Spatial Decision Support System, Location Allocation Models, Location Efficiency, Location Equity.

\section{Introduction}

Health care service provision and access have been a major factor that contributes to a healthy population (Phillips, 1990; Kumar, 1999; Guagliardo, 2004; Bagheri et al., 2005).
It is in recognition of this importance of health care service that the International Conference on Primary Health Care held at Alma-Ala in 1978 advocated for reduction in health inequalities, especially in the poor countries and there 
was a renewed interest in equity in health in the late 1990s (Gwatkin, 2000). Moisi et al. (2010) identified that our knowledge of geographic inequities in health is limited, where equity is defined as a just spatial distribution of resources in relation to need (Talen, 2001). Attempt to achieve equitable distribution of health services can be difficult especially where the type of care requires expensive equipments and specialist's care like in mental health care.

In Nigeria, the prevalence of mental illness is reported at $20 \%$ and there has been a steady growth in the number of mentally ill patients roaming the streets (University of Ibadan, 2012). Guruje (2016) estimated that one out of seven persons in Nigeria will have serious mental illness, while one in four will have some form of mental disorder. However, access to mental health care facilities is poor and their distribution is not equitable in Nigeria. Jack-Ide (2012) identified that the state and federal psychiatric hospitals in Nigeria are only located in the urban areas making it difficult for those in the rural areas to access the care they deserve. According to a report on the mental health situation in Nigeria, it has been estimated that at least, about 90 percent of people with clear cut mental health syndromes do not even get any treatment at all and that the ratio of psychiatrists to population is 1:1,400,000 (University of Ibadan, 2012). Poor access to orthodox mental health facilities partially accounts for majority of mentally ill and their relatives seeking for alternative sources of care in unorthodox and traditional psychiatric institutions (Ewhrudjakpor, 2010). However, it is the right of the people to have access to health services and it is the obligation of the government to provide health facilities in an efficient and effective manner. It is the aim of this study to provide a spatial decision support system (SDSS) to aid in selecting some specific locations for specialized health care provision out of existing health centres. Efficiency and equity are the location objectives considered in the design of the SDSS. The experience of a government owned National NeuroPsychiatrist Hospital in Nigeria has been used in this study. The Hospital attempts to provide community based mental health services in one of the states in the Country. This national hospital selected two existing primary health centres (PHC) in each of the five local government areas used for this study and provides mental health services in them. The location-allocation modeling approach has been used to evaluate the locations of the chosen PHCs in the study area and to provide an alternative location plan that will give a more equitable distribution of mental care services. To execute the suggested location plan the new locations will simply involve the movement of personnel and equipment from the dropped PHC to the recommended PHC. One approach that has been used by researchers to evaluate location of health facilities in rural regions of developing countries islocation-allocation modelling (Rushton, 1988; Ayeni, 1986, SinuanyStern et al., 1995, Schilling, 1988, Rahman and Smith, 2000, Owoola, 2002, VallimFo and Silva Mota (2012), Tanser, 2006) and this approach has been adopted in this study. Generally, location-allocation (L-A) problem is concerned with the siting of one or more facilities (the location problem) and the 
allocation of consumers to these facilities in a way that optimizes certain objectives (called the objective function) such as: minimizing transportation costs/ distance traveled, maximizing population covered or maximizing market share/ profit. There are many variants of L-A models. The most commonly used L-A models are those based on minimizing distance and those based on maximizing coverage (Ghosh and Rushton, 1987).

\section{Study Area}

Yewa region in Ogun State is the study area for this work and it is made up of five local government areas, namely: Ado-Odo/Ota, Imeko/Afon, Ipokia, Yewa north and Yewa south local government areas. The region has been chosen for this study because it is at the fringe and is marginal to Ogun State also it is comparatively disadvantaged in terms of public health facilities provision. For example as at $200929.7 \%$ of all the population of Ogun State could be found in Yewa region, but only $24.1 \%$ of all public health facilities in Ogun State were in the region. Yewa region lies at the western end of Ogun state. The region lies between Latitudes $6^{\circ} 26^{\prime}$ and $7^{\circ} 56^{\prime}$ North of the Equator; and Longitudes $2^{\circ} 41^{\prime}$ and $327^{\prime}$ East of the Greenwich Meridian. See Figure 1 for the location map of Yewa region. The total land area of the Region is 5,801.68 sq kilometers. The modes of transport available in Yewa region are road, rail and water. Roads are mainly used for accessing public facilities in the Region.

Mental Health Care Service in the Study Area

Mental health services are provided mainly in ten regional psychiatric hospitals owned by the federal and state governments in Nigeria. There are 24 general hospitals that have mental health care units and also 8 mental care centres are owned by NGOs and other private groups ((Department of Psychiatry, University of Ibadan, 2012). In the study area ten out of the existing 116 primary health centres (PHC) were selected where mental health care services were established by the Neuro-psychiatrist Hospital, Abeokuta. 


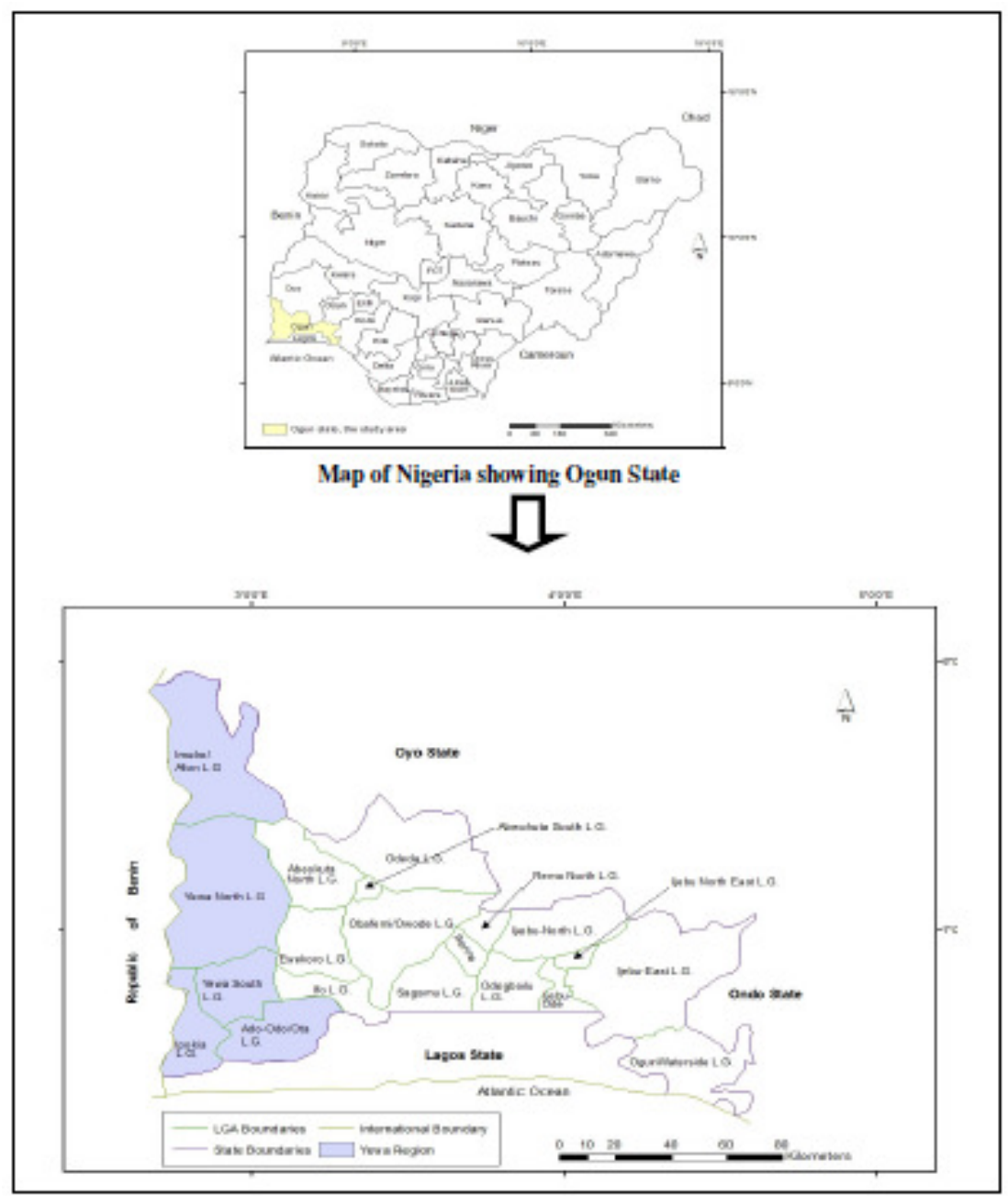

Figure 1: Map of Ogun State showing Yewa Region

\section{Methodology}

\section{The Dataset}

The dataset used in this study are integrated within the database management system provided by $\operatorname{ArcGIS}^{\circledR}$ v10, a software by ESRI. The software facilitates the development and management of spatial and attribute databases that are critical to the study.

The data used in this study include the 2015 projected population sizes and the coordinates of all the 501 identifiable settlements in Yewa Region of Ogun state. The population sizes serve as the surrogate for the demand for health facilities. The coordinates of the location of all the settlements are obtained from the 1: 75,000 topographic maps of the study area produced by Ministry of Lands and Housing, Ogun State. Paper copies of the maps were scanned and the digital versions were stored in the database of ArcGIS 10. Coordinates of four to six points were obtained from the maps of the study area and cross checked with those obtained by using a Magellan Triton GPS for the same locations. The coordinates obtained for the selected locations were used to georeference the scanned digital maps in ArcGIS 10. 
Other data for the study include the coordinates of the location of all the primary health centres (PHC) in the study area obtained from the Ogun State Health Bulletin (2010). The location of all the PHCs providing mental health services were obtained from the Federal Psychiatrist Hospital, Abeokuta. The map of road transport networks within the study area was updated from the topographic maps. The transport network in the area consists of the footpaths, secondary roads and main roads.

The location- allocation (L-A) models embedded in ArcGIS 10 has been used

$$
\begin{aligned}
& \text { Mirimize } Z=\sum_{i} \sum_{j} a_{i} x_{i j} c_{i j} \\
& \text { subject to } \sum_{j} x_{i j}=1 \forall i \\
& \sum_{j} x_{j j}=p \\
& x_{j j}-x_{i i} \geq 0 \\
& \text { and } x_{i j} \geq 0
\end{aligned}
$$

and the model options used include the pmedian, the maximize covering and the minimize facilities models. The application of the models assumes that settlements are allocated to the nearest health facility providing mental care.

The p-median location model is widely applicable to the siting of public facilities. It determines the location on a network of public facilities and the allocation of consumers such that the total or average distance or cost is at a minimum. The mathematical description of the p-median model is given below (Ayeni, 1992).

Where $c_{\mathrm{ij}}$, the distance between the points of demand $\left(\mathrm{x}_{\mathrm{di}}, \mathrm{y}_{\mathrm{di}}\right)$ and the supply points $\left(\mathrm{x}_{\mathrm{j}}, \mathrm{y}_{\mathrm{j}}\right)$ is defined as:

$$
c_{i j}=\left[\left(x_{d j}-x_{i j}\right)^{2}+\left(y_{d j}-y_{i}\right)^{2}\right]^{1 / 2}
$$

\section{Results and Discussion}

\section{Spatial Distribution of Mental Health Care Centres}

The primary objectives for locating public health facilities to be examined using the SDSS framework are to minimize users' distance to the facilities, to locate the facilities such that the number of people without access to facilities would be minimized and to conserve resources while providing the facilities.
Table 1 depicts some salient statistics on the spatial distribution of the ten chosen PHCs by the Federal Psychiatrist Hospital in Yewa region for providing mental health care. The combined population of the 10 settlements containing mental health care centres (MHC) represents $42.53 \%$ of the total population. Settlements without mental health services are 491 and their population represents $57.47 \%$ of the total population. The inference from the 
distribution pattern is that the MHCs tend to be located in centres with large concentration of the total population.
Also results in Table 1 shows that about $74.85 \%$ of the settlements are more than ten kilometers from the nearest MHC.

Table 1: Spatial Distribution of Community Mental Health Facilities in Yewa Region

\begin{tabular}{ll}
\hline Attributes of service delivery & Statistics \\
\hline Total population of study region & $1,078,027$ \\
Total number of settlements & 501 \\
Number of settlements with mental health facilities & 10 \\
Percentage of settlements with facilities & $2 \%$ \\
Percentage of settlements without facilities & $98 \%$ \\
Percentage of population in centres with facilities & $42.53 \%$ \\
Percentage of population in centres without facilities & $57.47 \%$ \\
Settlements that are above 10km from nearest PHC & 375 \\
Percentage of settlements that are above 10km from nearest PHC & $74.85 \%$ \\
\hline
\end{tabular}

Source: Generated from the location-allocation procedure of ArcGIS10

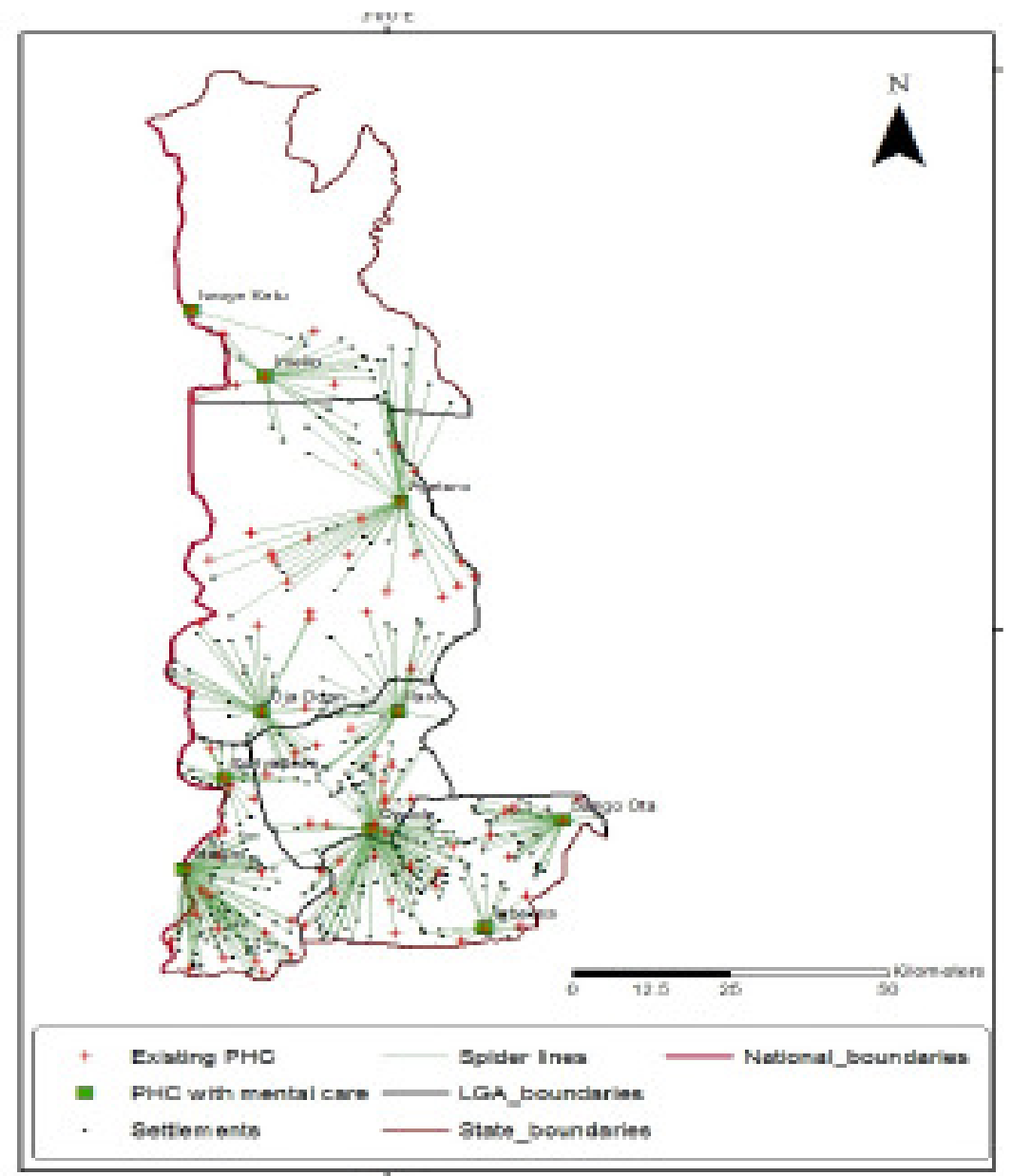

Figure 2: Actual locations of primary health centres offering mental health services 


\section{Efficiency and equity in the locational analysis of mental health care facilities in the study area}

Planning the location of specialized health care facilities, to ensure equity, can be challenging because of the limited resources and specialists often required. However, it is the obligation of government to provide such facilities for the benefit of its citizens. Where these facilities are located without regard to the distribution of population, government could be ineffective in meeting its obligation. Thus an attempt is made to examine how the government would have been able to meet its obligations efficiently and effectively if use had been made of a planning framework that allows the evaluation of existing service delivery patterns and help to improve on the existing location plan. To demonstrate the application of such a framework the location-allocation models have been used in an SDSS in this study.

In public facilities planning it is a good practice to evaluate the existing pattern of facilities by comparing it with an optimal pattern. This will allow us find a better way to organize facilities in order to eliminate wastage. The existing pattern of distribution of mental health care centres (MHC) and the allocation of settlements to these facilities in the study area is shown in Figure 2. The settlements were allocated to the closest facility (it is assumed that users will visit the nearest health facility). The application of the minimize distance (pmedian) option of the location-allocation (L-A) model component of the SDSS framework in this study generates part of the statistics in Table 2. There are currently $10 \mathrm{MHCs}$ in the study area. It is shown that if the Federal Psychiatrist Hospital Management (FPHM) had paid attention to optimality in planning the locations of the MHCs the average distance travelled could be reduced from $15.3 \mathrm{~km}$ to $14 \mathrm{~km}$. The efficiency of the existing configuration is $91.5 \%$. The geographical efficiency is derived by comparing the distance travelled in the modeled pattern with the distance in the existing distribution pattern of health facilities. The efficiency in this case is high because the decision makers have chosen to locate the MHCs in most of the available urban centres with high population concentration. To minimized the distances travelled, the $\mathrm{p}$ median model also favours centres with large population.

Table 2: Mental Health Care Services Delivery

Distance factor

\begin{tabular}{llll}
\hline $\begin{array}{l}\text { Attributes of service } \\
\text { delivery }\end{array}$ & Existing pattern & $\begin{array}{l}\text { Minimise Distance (P- } \\
\text { Median) pattern }\end{array}$ & $\begin{array}{l}\text { Minimize Facilities } \\
\text { pattern }\end{array}$ \\
\hline & & 10 & 21 \\
Number of facilities & 10 & 14 & 9.4 \\
$\begin{array}{l}\text { Average travel } \\
\text { distance }(\mathrm{km})\end{array}$ & 15.3 & 47.81 & 19.44 \\
$\begin{array}{l}\text { Maximum distance } \\
\text { ever travelled }(\mathrm{km})\end{array}$ & 48.66 & & \\
\hline
\end{tabular}


A Spatial Decision Support System for Special Health Facility Location.................0TUN, 0.W.

Coverage Factor

\begin{tabular}{|c|c|c|c|c|}
\hline \multirow[t]{2}{*}{ Attributes of service delivery } & \multicolumn{4}{|c|}{ Statistics for the Study Area } \\
\hline & $\begin{array}{l}\text { Existing } \\
\text { pattern }\end{array}$ & $\begin{array}{l}\text { Maxima } \\
\text { Coverin }\end{array}$ & tern & $\begin{array}{l}\text { Minimize Facilities } \\
\text { pattern }\end{array}$ \\
\hline $\begin{array}{lll}\begin{array}{l}\text { Maximum } \\
\text { coverage }\end{array} & \text { distance } & \text { for } \\
\end{array}$ & $10 \mathrm{~km}$ & $10 \mathrm{~km}$ & $20 \mathrm{~km}$ & $20 \mathrm{~km}$ \\
\hline Number of facilities & 10 & 10 & 10 & 21 \\
\hline $\begin{array}{l}\text { Number of settlements } \\
\text { covered }\end{array}$ & 126 & 196 & 432 & 494 \\
\hline $\begin{array}{l}\text { Percentage of settlements } \\
\text { covered }\end{array}$ & $25.15 \%$ & $39.12 \%$ & $86.23 \%$ & $98.6 \%$ \\
\hline Population in centres covered & 614,299 & 710,886 & $1,024,346$ & $1,068,525$ \\
\hline $\begin{array}{l}\text { Percent of population in } \\
\text { centres covered }\end{array}$ & $56.98 \%$ & $65.94 \%$ & $95.02 \%$ & $99.12 \%$ \\
\hline
\end{tabular}

Source: Generated from the location-allocation procedure of ArcGIS10

It has been observed earlier that decision makers tend to locate MHCs in areas of population concentration and that $74.85 \%$ of the settlements are more than ten kilometers from the nearest mental health care centre (MHC). These observations will negate the equity objective of government in service delivery. The notion of equity evolved from the need to protect that segment of the society less able to compete in the national/regional space economy (Owoola, 1996). Morrill and Symons (1977) considered the use of some measures of locational equity such as a socially imposed minimum standard. In an attempt to demonstrate how the SDSS framework can be used to operationalise the concept of equity, based on distance standard, it is shown that the Federal Psychiatrist Hospital Management (FPHM) can use the maximal covering model of the SDSS to examine different locational equity scenarios in form of 'what if analysis?' It is demonstrated in table 2, the statistics for the location plan if the decision makers want to maximize the number of users that are covered within 10 and $20 \mathrm{~km}$ of the MHCs. It is shown in table 2 that by applying the maximal covering model, 10 facility locations can be used to ensure that $65.94 \%$ of the population do not travelled more than $10 \mathrm{~km}$ compared to $56.98 \%$ in the existing location pattern. The model can also be used to find locations for the 10 facilities to ensure that $95.02 \%$ of the population do not travelled more than $20 \mathrm{~km}$ to the nearest MHC.

To improve the service delivery both in terms of coverage of the population and the distance travelled by the users of MHCs, the minimize facilities model option of the SDSS can be used to find the minimum number of facilities required to cover the maximum population. This model option allows decision makers to maximize resources. The application of this model option shows that 21 facilities are required to ensure that the average travel distance is $9.4 \mathrm{~km}$ and that $99.12 \%$ of the population do not travel more than $20 \mathrm{~km}$ to get to the nearest MHC. The location of the 21 chosen health facilities and the allocation of settlements to them is shown in figure 3. 
The SDSS approach to public facility location planning in this study shows how specialized health care services can be provided in existing facilities to achieve pre stated location objectives in the face of limited available resources. Where the model recommended location plan is different from the existing plan, the implementation of the model recommended location plan will not involve the erection of new buildings, which could be expensive. The reallocation of the specialized services are restricted to existing health care structures. The re-allocation will only involve the movement of the personnel and equipments from the current facility to the recommended facility.

This study demonstrated how equity and efficiency concepts can be operationalised using location-allocation models in planning the location of public health facilities. Some previous studies have identified inequities in the distribution of health facilities but they did not show how such the policy makers can address such inequities (Zenk, 2006).

A key aspect of study of geographic access to health facilities is the measure of the separating distance between the facility and the users. Actual physical distance, perception of such distance, travel time and cost have been used to measure the friction of distance between facilities and users. In this study movements along the road networks and foot paths have been used, unlike some previous similar studies that used Euclidean distances between facilities and the users ( Ayeni et al., 1985, Ayeni and Rushton, 1986, Owoola, 2002). The use of the actual road networks is more realistic and a number of studies have revealed differences in outcome between straight line distance analysis and that based on actual transport network (Tanser, 2005). However the impedance of drainages across the road networks has not been accounted for in this study, also the effect of elevation has not been factored into modeling movement along the network as the differences in elevation in the study area are not that pronounced. Future researches can use travel time to measure physical access in a study like this given that different means of transport are often used and this could have implications on access to health facilities.

In this study it is assumed that the people will visit the nearest health facility, some studies have shown that this is not always true. Some health care seekers often bypass lower quality service to attend facilities providing higher quality services (Klemick et al., 2009). However in a study by Noor et al. (2003) it was found that there is a correlation between actual and potential/ theoretical usage of public health facilities in Kenya. 


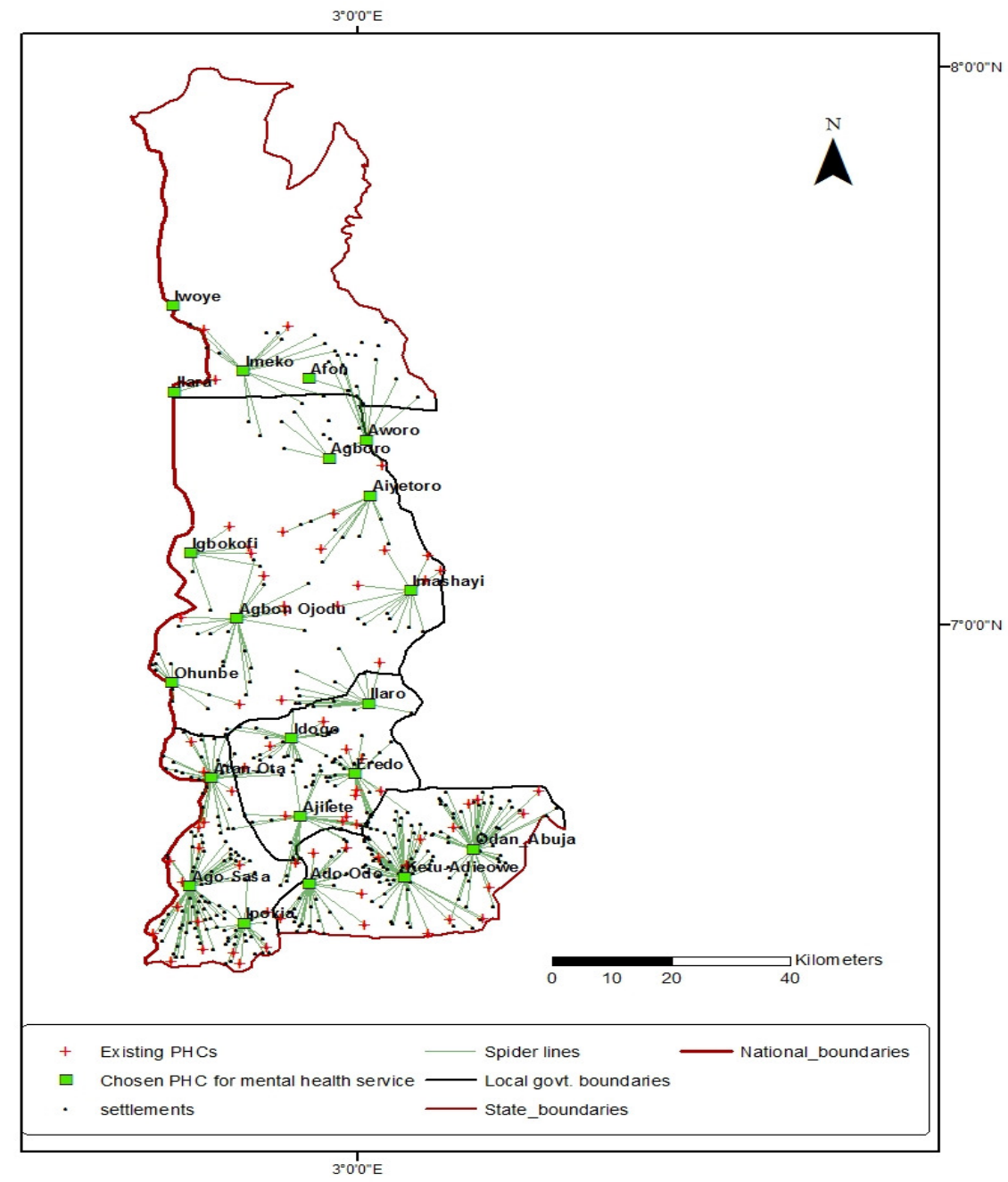

Figure 3: Locations of the minimum number of facilities to ensure maximum coverage of the population

\section{Conclusion}

This study has demonstrated that it is possible to make operational, using a SDSS framework, problems of optimally allocating scarce resources facing decision-makers in service development planning. The application of the SDSS framework in this study has shown how to evaluate existing spatial configuration of public health facilities and to provide critical health care services in a more rational way in the face of limited available resources. Particularly it has shown how theoretical location concepts can be translated into practical tools of decision making. Thus it is hoped that health planners trying to maximize limited available resources, especially in critical areas of health care services would adopt these techniques and tools to make their location decisions more efficient, equitable and rational.

\section{Acknowledgement}

The author wish to gratefully acknowledge the support received from 
the management of the Neuropsychiatrist Hospital, Aro, Abeokuta, Nigeria for the use of data on the location of mental health care services provided in Ogun State.

\section{References}

Ayeni, B., Rushton, G. and McNulty, M. (1985). An Analysis of the Efficiency of the Location of Secondary Schools in Some Rural Areas of Ogun State', the Nigerian Journal of Economic and Social Studies, 27(3): 345-369.

Ayeni, B. and Rushton, G. (1986). Distributional equity and efficiency in the locational analysis of public facilities: a case study, The Nigerian Geographical Journal, 28-29(1-2):115-136.

Ayeni, B. (1992). A place for everything, University of Ibadan 1991/92 Inaugural Lectures, University of Ibadan.

Ayeni, B. (2010). The Practitioner's Guide to Geographic Information Systems, Spatial Analysis and Spatial Decision Support Systems. Ibadan: Research Support Services.

Bagheri, N., George, L.B. and Alec, H. (2005). Measuring Spatial Accessibility to Primary Health Care, Paper presented at the Annual Colloquium of the Spatial Information Research Centre, University of Otago, Dunedin, New Zealand, November, 2005.

Ewhrudjakpor, C. (2010). Psychiatric Institutions and the Emerging Institutional Scene in Nigeria, African Research Review, 4(1): 132- 147.

Ghosh, A. and Rushton, G. (1987). Introduction: Progress in Location-
Allocation Modelling", pp. 1-20 in Ghosh, A and Rushton, G. (eds.) Spatial Analysis and LocationAllocation Models, New York: Van Nostrand Reinhold.

Guagliardo, F.M. (2004). Spatial Accessibility of Primary Care: Concepts, Methods and Challenges, International Journal of Health Geographics, 3(3). Available at: wWw.ij-

healthgeographics.biomedcentral.co $\mathrm{m} /$ articles/10.1186.

Guruje, O. (2016). Increased Rate of Mental Disorder Among Nigerians Worries Expert, Premium Times, July 10, 2016.

Gwatkin, D. R. (2000). Health Inqualities and the Health of the Poor: What do we know? What can we do? BullWorld Health Organ, 73(1): 318.

Jack-Ide, I.O., Uys, L.R. and Middleton, L.E. (2012). A comparative study of mental health services in two African countries: South Africa and Nigeria, International Journal of Nursing and Midwifery, 4(4): 50-57

Klemick, H., Leonard, K. L and Masatu, M. C. (2009). Defining Access to Health Care Evidence on the Importance of Quality and Distance in Rural Tanzania, American Journal of Agricultural Economics, 91(2): 347-358.

Kumar, N. (1999). "Locational Analysis of Public and Private Health Services in Rohtak and Bhiwani Districts, (India), 1981 to 1996", Centre for the Study of Regional Development, India.

Morrill, R.L. and Simons, J. (1977). Efficiency and Equity Aspects of 
Optimum Location, Geographical Analysis, 9(3): 215-225.

Noor, A.M., Zurovac, D., Hay, S.I., Ochola, S.A. and Snow, R.W. (2003). Defining Equity in Physical Access to Clinical Services Using Geographical Information Systems as Part of Malaria Planning and Monitoring in Kenya, Tropical Med Int Health 8(10): 917-926.

Ogun State Government (2010a). Draft of the Ogun State Strategic Health Development Plan, 2010.Ministry of Health, Abeokuta, Nigeria.

Ogun State Government (2010b). Ogun State Health Bulletin, Vol. 4, 20072009, Ministry of Health, Abeokuta, Nigeria.

Ogun State Government (2010c). Central Department of Statistics, Ministry of Finance, Oke-mosan, Abeokuta.

Owoola, M.A (1996). Location of Public Facilities: A Spatial Decision Support Systems Approach, Unpublished Ph.D. Thesis University of Ibadan, Nigeria.

Owoola, M.A. (2002). Between policy and practice decision support system-based assessment of facility location planning in Nigeria, paper presented at a symposium on geospatial theory, processing and applications, Ottawa.

Phillips, D.R. (1990). Health and Health Care in the Third World, New York: Longman, Scientific and Technical.

Rahman, S.U. and Smith, D.K. (2000). Use of location- allocation models in health service development planning in developing nations, European Journal of Operational Research, 123.
Rushton, G. (1988). The Roepke Lecture in Economic Geography: Location Theory, Location-Allocation Models, and Service Development Planning in the Third World. Economic Geography, 64: 97-120.

Sinuany-Stern, Z., Mehrez, A., Tal, A.G.and Shemuel, B. (1995), The location of a hospital in a rural region: The case of the Negev, Location Science, 3: 255-266.

Talen, E. (2001). School, Community and Spatial Equity: An Empirical Investigation of Access to Elementary Schools in West Virginia, Annals of the Association of American Geographers, 91(3): 465-486.

Tanser, F. (2006). Methodology for optimizing location of new health care facilities in rural communities: a case study in KwaZulu Natal, South Africa, Journal of Epidemiol Community Health, 60(10): 846850.

University of Ibadan (2012). Mental Health Situation Analysis in Nigeria, Mental Health and Leadership and Advocacy Programme, Department of Psychiatry, University of Ibadan, Nigeria.

VallimFo, A. and Silva M.I. (2012), Optimization models in the location of health care facilities: The case of the Brazil, Journal of Applied Operational Research, 4(1):37-50.

Zenk, S.N., Tarlov, E. and Sun, J. (2006). Spatial Equity in Facilities Providing Low-or No-Fee Screening Mammography in Chicago Neighbourhoods, J Urban Health, 83(2): 195-210. 